\title{
A ESCRITA DE UM CORPO SEM ÓRGÃos
}

Catarina Resende ${ }^{\star}$

\begin{abstract}
ReSUMO
A partir da leitura dos estudos de Foucault sobre o cuidado de si e de Deleuze e Guattari sobre o corpo sem órgãos (CsO), tivemos o objetivo de traçar as possíveis aproximações entre a escrita de si e o diário de CsO. Esse exercício de escrita de si constitui um exercício de constituição de corpos que além de um voltar-se sobre si, oferece um cuidado de si para cuidar dos outros. Concebemos o diário de $\mathrm{Cs} O$ enquanto uma prática de si que oferece um movimento etopoiético na direção de uma dimensão ética e estética, mas também política da vida.
\end{abstract}

Palavras-chave: Cuidado de si. Corpo sem órgãos. Ética. Estética. Subjetividade.

\section{THE WRITING OF A BODY WITHOUT ORGANS}

\begin{abstract}
Beginning from the reading of the Foucault studies on the self care and of Deleuze and Guattari on the body without organs, we had for purpose to trace the possible approximations between the self writing and the body without organs diary. This exercise of self writing is an exercise of constitution of bodies that, besides turning back over oneself, provides a self care in order to care for the others. We conceived the body without organs diary as an ethopoietic movement towards an ethical and esthetic dimension, but also political of life.
\end{abstract}

Keywords: Self care. Body without organs. Ethic. Esthetic. Subjectivity.

\footnotetext{
^ Instituto de Estudos em Saúde Coletiva (IESC) da Universidade Federal do Rio de Janeiro (UFRJ) - mestranda. Endereço para correspondência: Av. Prefeito Dulcídio Cardoso, 800/b.2, 801. Barra da Tijuca, Rio de Janeiro, RJ. CEP: 22620-311.

E-mail: catarinamr@terra.com.br
} 


\section{Embusca de uma est ét ica da exist ência}

A partir da sua investigação sobre a história da sexualidade, Foucault passa a problematizar os processos de subjetivação do ponto de vista "do governo de si”. Seus últimos escritos, já na década de 1980, se dedicam à constituição do sujeito na sua relação consigo e com os outros, e ao tema da conduta de vida. Para tanto, estuda a moral da Antiguidade ao cristianismo, lançando um olhar para o passado, a fim de pensar questões atuais que dizem respeito ao ser. Segundo ele, a moral cristã de obediência a um sistema de regras encontra-se em decadência e até mesmo desaparecendo, o que justifica o interesse pela Antiguidade para se pensar formas de subjetivação enquanto práticas de liberdade (FOUCAULT, 1984a/2004, 1984b/2004). O estudo de uma moral que vai ao encontro de uma ética pessoal pode nos oferecer uma reflexão sobre o que vivemos hoje, na busca por uma estética da existência (FOUCAULT, 1984c/2004).

Foucault localiza entre os séculos I e II o período de maior desenvolvimento de uma "arte da existência" que se constitui no que ele entende por "técnicas de si": um conjunto de procedimentos, pressupostos ou prescritos destinados à fixação, manutenção ou transformação das identidades dos indivíduos em função de determinados objetivos, a partir das relações de domínio de si sobre si (FOUCAULT, 1980-1981/1997, p. 109). Com uma pesquisa sobre os modos estabelecidos de conhecimento de si, Foucault problematiza não só a constituição do sujeito na complexidade de suas interações com o outro, mas, também, o imperativo socrático do "conhece-te a ti mesmo".

Tais estudos nos remetem a uma dimensão da subjetividade derivada do poder e do saber, mas que no entanto deixa de ser correlativa e dependente deles (DELEUZE, 1991). Ao deslocar a questão da subjetividade do eixo poder-resistência, podemos criar uma nova relação com o poder, este agora, tomado como correlativo e dependente da liberdade. Nesta dimensão a conquista da liberdade se dá a partir da ética. A reflexão de Foucault nos coloca questões atuais como: "Que fazer de si mesmo?", ou, "Que trabalho operar sobre si?" (FOUCAULT, 1980-1981/1997, p. 109-110).

$\mathrm{Na}$ apresentação de seu curso sobre o tema da hermenêutica do sujeito, Foucault remonta um cenário onde "a regra de ter de conhecer a si mesmo foi regulamente associada ao tema do cuidado de si" (FOUCAULT, 1981-1982/1997, p. 119), e nos traz exemplos da cultura antiga sobre o valor dado ao cuidado de si e sua relação com o conhecimento de si. Foucault considera que o Alcebíades de Platão marca o ponto de partida para a questão do cuidado de si - epimeleïa heautou - quando se confere significação ao imperativo do conhecimento de si (FOUCAULT, 1980-1981/1997). A partir de extremos como Sócrates e Gregório de Nícia, vemos tanto a filosofia antiga quanto o ascetismo cristão "sob o signo do cuidado de si”, não apenas como um princípio, mas como uma prática constante (FOUCAULT, 1981-1982/1997, p. 120). 
Entretanto, nosso objetivo não é o de discorrer acerca da diferença entre as práticas dos gregos e dos cristãos, mas de pensar em possíveis práticas de si que se insiram no contexto do nosso tempo e que possam nos abrir para uma ética da liberdade. O cuidado de si será entendido aqui de acordo com o que sugere Foucault, como experiência e como técnica elaborada que transforma essa experiência. No entendimento de Deleuze, os gregos "inventam" o sujeito como derivado de uma "subjetivação", eles descobrem a "existência estética" na relação consigo como regra facultativa do homem livre (DELEUZE, 1991). Dessa forma, ao fazer uma história do cuidado de si, Foucault faz também uma história da subjetividade que põe em destaque o sujeito nas suas experiências, na articulação do governo de si com as relações com o outro (FOUCAULT, 1980-1981/1997).

Para tanto, gostaríamos de lançar o nosso olhar para os textos sobre os modos de vida na cultura greco-romana no que diz respeito ao conjunto de atividades que constituem práticas de si: exercícios, dietas, regimes de sono e vigília, atividade sexual, cuidados corporais, meditações, leituras etc. No entanto, destacaremos para fins de nossa análise, a "escrita de si" como um exemplo de "arte de si mesmo" e governo de si e dos outros. A escrita de si da cultura filosófica anterior ao cristianismo deve ser vista como uma das práticas de si, treino de si por si mesmo. Ou seja, nenhuma técnica pode ser adquirida sem exercício: "a arte de viver" deve ser conquistada dia após dia, durante toda a vida, num campo de atividades complexas, reguladas e cuidadosamente elaboradas (FOUCAULT, 1981-1982/1997, 1983a/2004, 1983b/2004).

A escrita dos séculos I e II nos interessa particularmente pela função etopoiética que é capaz de assumir, enquanto opera a "transformação da verdade em êthos" (FOUCAULT, 1983a/2004, p. 147). Suas formas mais conhecidas são o hupomnêmata e a correspondência.

Os hupomnêmata eram utilizados por um público culto como guia de conduta através de anotações sobre citações, fragmentos de obras, ações e lembranças, entre outras. Seu valor ia além de "uma memória material das coisas lidas, ouvidas ou pensadas", constituindo essencialmente "um tesouro acumulado para releitura e meditação posteriores" (FOUCAULT, 1983a/2004, p. 147). Mais que simples cadernetas de anotações ou suportes de memória, os hupomnêmata estão arquivados na alma, como diz Sêneca, fazendo parte de si mesmo. A sua escrita, portanto, nada mais é que subjetivação do discurso, constituição de si. Nesta ética os objetivos são claros: "recolher-se em si, atingir a si mesmo, viver consigo mesmo, bastar-se a si mesmo, aproveitar e gozar de si mesmo" (FOUCAULT, 1983a/2004, p. 149). Sem se preocupar com o futuro, os hupomnêmata direcionam sua reflexão para o passado, opondo-se à dispersão da stultitia ${ }^{\text {a }}$. Sem valor coercitivo, configura, nas palavras de Foucault, uma "prática regrada e voluntária do disparate" dominada por dois princípios que ele entende como "a verdade local da sentença" e "seu valor circunstancial de uso" (FOUCAULT, 1983a/2004, p. 51). Daí seu papel transformador. A escrita constitui um corpo, transforma o visto ou ouvido em "forças de sangue". Se no escritor ela se torna um princípio 
de ação racional, no copista, ela o permite criar sua própria identidade a partir da nova coleta de coisas ditas. Ou ainda, neste jogo de escrita e leitura podemos formar uma identidade onde se lê toda uma genealogia do que foi vivido.

As correspondências também permitem o exercício pessoal através de uma dupla função: age naquele que a envia, pelo gesto da escrita; e naquele que a recebe, pela leitura e releitura. Apesar de se assemelhar em alguns pontos com os hupomnêmata, as cartas não são seu simples prolongamento. Quando a carta torna o escritor presente para aquele que a recebeu, constitui uma forma de se manifestar a si mesmo e para os outros. Inerente a um conjunto de anotações sobre o corpo, a saúde, as sensações físicas, a dieta, os sentimentos, há uma verdadeira "escrita da relação consigo" com uma abertura ao outro sobre si mesmo no que diz respeito às interferências do corpo e da alma e às atividades de lazer (FOUCAULT, 1983a/2004).

Dessa forma, a proposta deste trabalho é fazer as possíveis aproximações entre os estudos de Foucault sobre cuidado de si e os de Deleuze e Guattari sobre o corpo sem órgãos, a fim de trazer à luz a reflexão sobre uma prática de si que, a nosso ver, favorece nos dias de hoje um caminho para uma estética da existência: o Diário de Corpo sem Órgãos.

\section{Como criar para si um diário de corpo semórgãos}

Se quiserem, podem meter-me numa camisa de força, mas não existe coisa mais inútil que um órgão. Quando tiverem conseguido um corpo sem órgãos, então o terão liberado dos seus automatismos e devolvido sua verdadeira liberdade.

(Antonin Artaud, 1947/1983, p. 161)

Na transmissão radiofônica de Para acabar com o julgamento de Deus, Artaud nos apresenta um corpo não organizado que teria sido roubado por Deus para nos submeter ao juízo. Ao encontrar o nosso corpo sem órgãos poderemos escapar do julgamento e produzirmos um "corpo afetivo, intensivo, anarquista, que só comporta pólos, zonas, limiares e gradientes” (DELEUZE, 1997, p. 148).

Deleuze e Guattari se apropriam da idéia de um corpo sem órgãos de Artaud e dão continuidade a ela com alguma ressalva: "não é uma noção, um conceito, mas antes uma prática, um conjunto de práticas" (DELEUZE; GUATTARI, 1980/2004, p. 9). O corpo sem órgãos (CsO) é o corpo da experiência, com suas próprias forças. É o corpo livre da interpretação e do juízo que nos impedem novos modos de vida e organizam os corpos. O CsO não se opõe aos órgãos do corpo, mas sim ao corpo organismo enquanto "organização orgânica dos órgãos" (DELEUZE; GUATTARI, 1980/2004, p. 21). Sem o aprisionamento em um corpo organicamente organizado, podemos nos abrir ao fluxo, ao devir, à intensidade, à experimentação de nós mesmos. Criar para si um $\mathrm{CsO}$ é se deixar atravessar por uma poderosa vitalidade não-orgânica (DELEUZE, 1997). 
É evidente que também nos constituímos em um corpo organismo, mas não devemos depender dele, o que é bem diferente. Quando dependemos do organismo, estamos presos a padrões estabelecidos pela sociedade, ficamos vulneráveis a censuras, repressões, regras, interpretações e automatismos. O CsO é o oposto disso, ele não reprime os impulsos, pertence a uma conexão de desejos, a uma conjunção de fluxos; acontece por intensidades que estão associadas à vitalidade e à existência enquanto criação contínua. $\mathrm{O} \mathrm{CsO}$ não é um não-corpo, mas um corpo instituinte.

Mas é preciso prudência! Articular esses desejos e conexões para criar um CsO não é tarefa simples. De acordo com Deleuze e Guattari (1980/2004), quando essa abertura aos acontecimentos se dá num corpo extremamente fixado na organização orgânica dos órgãos, ele pode se perder nesse turbilhão de intensidades e se enrijecer num determinado tipo de corpo, como o hipocondríaco, o drogado, o masoquista e o esquizofrênico.

É verdade que todos esses corpos podem ser ainda $\mathrm{CsO}$, mas é preciso saber transitar entre eles, desprender-se do organismo para não sucumbir num $\mathrm{CsO}$ vazio. Temos que saber manejar os impulsos e os desejos para criarmos um CsO pleno de potência e assegurar ao corpo essas conexões contínuas. Para Deleuze e Guattari (1980/2004), o CsO está sempre por acontecer, ele se cria no plano de imanência, pertence ao mundo do terreno, das vivências, dos modos de ser. O corpo não é hermético, acabado e constituído, mas uma derivação, um somatório de forças. Cada vivência é sempre singular e ao mesmo tempo múltipla. O CsO não deve se submeter à interpretação e ao julgamento, ele está associado à descrição e ao relato das experiências de si.

Portanto, é enquanto plano de experimentação de si que queremos abordar o diário de $\mathrm{CsO}$, mas não antes de contextualizarmos do que se trata esta prática. Ela foi criada na Escola Angel Vianna, no curso profissionalizante de Recuperação Motora e Terapia através da Dança, pelo Professor Mauro Costa para a disciplina "Seminário de Arte e Educação" a fim de inserir a experiência do $\mathrm{CsO}$ no meio da dança, utilizando-se do pensamento de Deleuze e Guattari sobre o corpo - associando-o aos de Artaud, Daniel Stern, José Gil, Suely Rolnik, Spinoza entre outros.

$\mathrm{O}$ resultado desse casamento me surpreendeu e continua me surpreendendo. Como a idéia era preparar os estudantes para escrever suas monografias, pedia, desde o fim do primeiro mês, que escrevessem, descrevessem, suas próprias experiências corpo sem órgãos. Afinal, Feldenkrais, Gerda Alexander, Alexander, todos fizeram seus programas de corpo sem órgãos, tanto quanto a improvisação do Paulo Trajano e a "expressão corporal" de Angel Vianna ou o corpo "oriental" do zen-shiatsu. A matemática qualitativa do corpo sem órgãos pede o acesso por meio da própria experiência: é um movimento construtivo e constituinte, principalmente um movimento político de desorganização construtiva... (COSTA, 2003, p. 60). 
Como vemos, nesta proposta, os alunos do curso devem registrar em um diário suas "experiências corpo sem órgãos", tanto em práticas mais expressivas e artísticas como a dança, quanto em atividades cotidianas, respeitando apenas o requisito de ser a descrição de um momento "corpo criando-se" (COSTA, 2003, p. 61).

Costa se refere às disciplinas ministradas no curso - Técnica de Feldenkrais, Eutonia, Técnica de Alexander, Contato e improvisação, Expressão corporal e Zen-shiatsu - que têm na própria prática descobertas de corpos sem órgãos. São práticas corporais que através de seus exercícios e orientações abrem o corpo ao fluxo de intensidades, num movimento de des-construção e re-construção do próprio corpo. Trata-se do que podemos chamar de "técnicas da imanência": não propõem um modelo a ser seguido ou atingido comum a todos os corpos, mas, ao contrário, criam um contexto de pesquisa corporal que valoriza as vivências de seus praticantes nas suas singularidades. Como nos sugere Teixeira (1998), é preciso que o corpo se conheça sozinho, sem dependência com o corpo organicamente organizado. Além disso, são técnicas que se utilizam de uma "pedagogia-terapêutica" , ou seja, disponibilizam meios para que o aluno se torne mais autônomo na manutenção do bem-estar corporal e na busca da sua saúde. Com maior conhecimento do seu corpo, ele adquire a capacidade de reconhecer seus ritmos e suas limitações - seja para respeitá-las ou superá-las - tanto físicas quanto psíquicas no enfrentamento das atividades diárias.

À medida que o diário de $\mathrm{CsO}$ constitui uma descrição do vivenciado com o máximo de intensidade e o mínimo de extensividade, sem juízo, sem interpretação, um verdadeiro "protocolo de experiências", ele faz da sua escrita um exercício de constituição de corpos. A proposta é descrever momentos em que deixamos de ser um corpo organismo para nos abrirmos a conexões, agenciamentos, circuitos, conjunções, intensidades e desterritorializações. Enfim, a proposta é escrever o diário dos nossos corpos sem órgãos.

A partir das palavras de um trecho do diário de $\mathrm{CsO}$ de um médico que freqüentou o curso, observamos o movimento de produção de mudanças na percepção e experiência do corpo.

Estava examinando uma senhora sentada na maca, eu auscultava seus batimentos cardíacos, seus pulmões, observando o murmúrio vesicular, sua natureza, intensidade e ruídos patológicos (roncos, sibilos etc.). De repente, comecei a prestar atenção na minha postura, e pude perceber que estava com a coluna cervical fletida, a região torácica cifótica (flexão anterior), a cabeça inclinada para a esquerda. A mão que segurava o estetoscópio no precórdio da paciente imprimia uma força e estava tensionada, o ombro esquerdo estava elevado e tenso e os ombros fechados. O peso do corpo estava mais sustentado na lateral direita, fazendo uma oposição. A região plantar que recebia o peso era a metade 
posterior dos pés, região dos calcâneos; era como se tivesse somente os calcanhares, não sentia os dedos e os metatarsos (COSTA, 2003, p. 68-69).

Na primeira parte desse relato podemos acompanhar o "exercício" aparentemente simples de "prestar atenção em si", mas que, de fato, demanda uma escuta refinada do próprio corpo. Quando conquistada, essa percepção pode produzir uma infinidade de informações e registros sobre o corpo no que tange às sensações, à organização interna e externa, e no que diz respeito ao espaço e a relação do corpo com os objetos e com os outros. Adiante veremos ainda no mesmo relato de que modo esse "exercício" se desdobra em um recurso que permite fazer um uso mais apropriado do corpo, potencializando suas ações.

Comecei a exercer a pausa e a inibição e, num gesto reflexo, quase desmontei este padrão de imediato. Depois, me dei um tempo, tomei consciência do meu momento corporal e fui aos poucos relaxando a mão que segura o estetoscópio, desci o ombro esquerdo, alarguei os ombros, desfiz a flexão cervical e torácica, assumi o peso nas duas lateralidades, solicitei uma atividade dos metatarsos e dos dedos e comecei a sentir toda a região plantar contra o chão. Com isto, fiquei mais alto em relação à altura do corpo da paciente que eu examinava. Então, fiz uma pequena flexão da coxofemoral, joelhos, e me vi na postura do macaco da técnica de Alexander. Isto me deu uma consciência das costas e de todo o comprimento da coluna, me senti mais presente, comecei a escutar os sons cardíacos e respiratórios de forma mais nítida, enfim, melhorou minha audição. (COSTA, 2003, p. 69)

Neste ponto do diário, o médico começa a perceber que a reorganização corporal experimentada vai além da reorganização de sua postura; trata-se de uma abertura do corpo como um todo à plenitude de suas funções. Observemos ainda:

Fiquei emocionado, não acreditei e resolvi fazer um teste. Abandonava a postura, e a audição dos sons se alterava, voltava à postura e percebia uma qualidade auditiva melhor. Imediatamente pensei: se Alexander melhorou sua voz com este trabalho, logo isto também se aplica a esta percepção e a todas as demais. Uma colega de trabalho veio me perguntar se eu estava com problemas de coluna, porque eu estava numa posição esquisita. Respondi que agora não; só estava fazendo uma pesquisa corporal (COSTA, 2003, p. 69).

Nesse caso, o autor do diário de $\mathrm{CsO}$ descreve com precisão e riqueza uma atividade extremamente corriqueira do cotidiano de um médico transformada em experiência sensível. Ele recorre aos recursos da técnica de Alexander que o permitem ampliar a percepção de si a fim de reorganizar sua postura e acaba criando uma desconstrução da sua atividade profissional. O estranhamento desse 
ato pôde abrir seu corpo à intensidade e à dimensão do outro, pois com uma melhor qualidade auditiva ele pode auscultar com mais precisão sua paciente. Essa experiência mostra como o jogo entre corpo organismo e $\mathrm{CsO}$ se dá num balanço contínuo, exatamente como vivemos.

A escrita de um diário sobre as experiências de um corpo não organizado é uma "escrita de sangue e de vida que se opõe à escrita do livro", sem o juízo, ela implica uma "verdadeira inversão do signo" (DELEUZE, 1997). O corpo se assume como lugar de potência e o sentido torna-se referência nas relações produzidas. Gostaríamos, portanto, de pensar o diário de $\mathrm{CsO}$ enquanto prática de cuidado de si que se constitui não apenas no campo da experiência, mas enquanto técnica elaborada que transforma a própria experiência.

\section{A escrita do CsO}

A fim de pensarmos alternativas para o imperativo do "conhecer a si mesmo", e de propor um trabalho que possamos operar sobre nós mesmos nos dias atuais sem função coercitiva, é que faremos nossa análise sobre o diário de $\mathrm{CsO}$ enquanto escrita de si. A nosso ver, o diário enuncia uma relação consigo que resiste aos códigos e aos poderes quando temos na relação consigo uma das origens dos pontos de resistência ao eixo saber-poder (DELEUZE, 1991). Entendemos o diário de $\mathrm{CsO}$ como uma técnica de si que suscita na escrita de si um instrumento de transformação etopoiético, onde ler o que se escreveu é reler a si mesmo.

A prática do diário de $\mathrm{CsO}$ permite um maior conhecimento de si que está relacionado aos modos de ser. Ele estabelece um modo de "exercício de si" que dialoga na sua estrutura, ora com os hupomnêmata ora com as correspondências desenvolvidos nos séculos I e II. Sem a intenção de definir limites estanques, na sua forma o diário de $\mathrm{CsO}$ se assemelha mais aos cadernos de anotações, porém no seu conteúdo aproxima-se mais das cartas. As experiências do ser, registradas no diário, constituem e subjetivam o corpo. Transformam o vivido em forças de sangue. Uma escrita da relação consigo reveladora dos movimentos da alma, mas, sobretudo, da carne.

Foucault, Deleuze e Guattari nos levam ao corpo como campo de forças, capaz de operar a inversão de signos e ir além do simbólico. A escrita do diário de $\mathrm{CsO}$ revela o corpo como uma máquina desejante e pulsante que ultrapassa seus contornos. O corpo ocupa lugar de investimento de desejo a partir de si mesmo, e não de sua representação imaginária ou simbólica. É o próprio corpo, encarnado, que produz o corpo na experiência e comporta todo o virtual do seu desejo. "O corpo é poder de transformação e devir" (GIL, 1997, p. 185).

Além de proporcionar um recolher-se em si mesmo, essa "escrita imanente das intensidades de si" também é um abrir-se para o outro. O diário de CsO põe em destaque não só o sujeito nas suas experiências, mas também na articulação do governo de si com as relações com o outro. Quando um aluno do curso da escola Angel Vianna trazia seus escritos para o restante da turma, podíamos observar que a leitura da experiência de um reverberava no outro, recriando e criando 
não o corpo sem órgãos "de um” ou "de outro", mas um corpo sem órgãos em continuum. No exercício em que um aluno lê para os demais suas próprias anotações e os penetra em seus corpos com isto, a escuta também atua de forma ativa na subjetivação do outro.

Assim, o diário de $\mathrm{CsO}$ nos oferece mais do que um voltar-se sobre si, pois aqui também podemos compreender a dimensão política do cuidado de si para cuidar dos outros. Para um cuidado de si enquanto forma de vida, a escrita, a leitura e a escuta do diário de $\mathrm{CsO}$ permitem um reinventar a si mesmo que não se limita ao autor da experiência registrada. Porém, este cuidado de si deve ser visto como uma tarefa; as relações consigo mesmo e com os outros devem ser estabelecidas ao longo de toda a vida a partir da conversão a si. Trata-se de um conhecimento de si que se dá pela sua função etopoiética, onde não devemos pretender uma verdade como decifração daquilo que somos, mas na nossa relação com o mundo, com os acontecimentos que se produzem. $\mathrm{O}$ diário de $\mathrm{CsO}$ revela uma verdade sobre si distante de uma hermenêutica do sujeito, ou melhor, de uma verdade dada da coisa em si; trata-se de uma verdade que está na própria experiência que nos constitui.

Entretanto, é importante retomarmos que, produzir um $\mathrm{CsO}$ exige prudência. Ir ao incodificável e desfazer o organismo pode ser tão devastador quanto os outros estratos que nos amarram enquanto sujeitos: a significância e a subjetivação. A prudência entra em jogo "como regra imanente à experimentação" (DELEUZE; GUATTARI, 1980/2004, p. 11). Paradoxalmente, é ela que nos permite ousar. Com prudência podemos avançar nas experimentações de nós mesmos, mas sempre podendo retornar delas quando assim desejarmos. Da mesma forma que não devemos estar sempre condicionados ao organismo, não podemos estar sempre no corpo sem órgãos. É preciso que haja um corpo organizado para abrir o corpo às intensidades, a fim de que se possa transitar entre esses gradientes.

Neste caso, a prudência se inscreve como uma charneira, uma bifurcação entre a expansão de um $\mathrm{CsO}$ potente nas suas conexões e a autodestruição de um $\mathrm{CsO}$ esvaziado de potência. Ela atua como uma verdadeira reguladora da liberdade. Daí a necessidade de se criar o CsO como um exercício do cuidado de si. Enquanto técnica de si é preciso conquistá-lo dia após dia, por um conjunto de práticas cuidadosamente elaboradas. As experimentações de si devem acontecer na arte da justa medida das possibilidades de agenciamentos de desejo de cada um, sem overdose.

Criar para si um $\mathrm{CsO}$ pleno é antes desconstruir o corpo - para que se possa construir outro(s) - e nunca destruí-lo. Como conduta de vida, criar um CsO requer necessariamente um lugar, um plano, um coletivo; tanto quanto o seu diário: temos que contextualizá-lo, mostrar "a verdade local da experiência" e "seu valor circunstancial de agenciamento de potências". 


\section{Umdiário da exist ência}

Como vimos, uma releitura da moral da cultura greco-romana nos permite repensar os modos de vida não em formas universais e coercitivas, mas sim contingentes e facultativas. Neste mesmo sentido, o diário de $\mathrm{CsO}$ nos oferece mais do que uma experiência pedagógica que encontrou terreno fértil para se desenvolver com sucesso no curso para o qual foi criado; ele anuncia a infinidade de relações do corpo com as forças que o afetam e nos oferece novos modos de subjetivação. Trata-se de um diário da própria existência.

Escrever e ler os movimentos do $\mathrm{CsO}$ opera um conhecimento de si onde o sujeito se apropria de uma verdade que não conhecia e que não residia nele como um dado em si. Uma arte da verdade imanente e díspar que combina a autoridade da coisa já vivida com a singularidade da própria existência que nela se afirma e a particularidade das circunstâncias que determinam seu uso.

Quando analisamos aqui o trecho de um diário de $\mathrm{CsO}$, percebemos que uma simples atividade do cotidiano é transformada em uma pesquisa corporal que potencializa o seu uso na relação consigo e com o outro. Nesse exemplo a arte de si mesmo se articula ao governo de si e dos outros, numa dimensão ética e estética, mas também política da vida.

Por fim, a prática de poder libertar o corpo de seus automatismos e escrever e ler sobre - e sob - a intensidade do CsO já agencia em si a sua função transformadora de reinvenção do sujeito. A arte do diário de $\mathrm{CsO}$, portanto, nos oferece um movimento em direção a uma ética pessoal que encontra na vida e na liberdade a própria estética da existência.

\section{Notas}

${ }^{1}$ De acordo com Foucault a stultitia pode ser caracterizada pela agitação, instabilidade, volatilidade e fragilidade diante dos acontecimentos que se produzem, além da perda de atenção com presente devido à preocupação com o futuro (FOUCAULT, 1983a, 150).

${ }^{2}$ Termo utilizado pelos eutonistas (HEMSY DE GAINZA, 1997) e aplicado livremente aqui às demais técnicas corporais citadas.

\section{REFERÊNCIAS}

ARTAUD, A. Para acabar com o julgamento de Deus (1947). In: WILLER, C. (tradução, seleção e notas). Escritos de Antonin Artaud. Porto Alegre: L\&PM, 1983.

COSTA, M. S. R. Dançando com o corpo sem órgãos. In: CALAZANS, J.; CASTILHO, J.; GOMES, S. (Coord.). Dança e educação em movimento. São Paulo: Cortez, 2003. p. 58-69.

DELEUZE, G. Para dar um fim ao juízo. In: . Crítica e clínica. Rio de Janeiro: Editora 34, 1997. p. 143-153.

Foucault. Tradução de Claudia Sant'Anna Martins. São Paulo: Brasiliense, 1991. 
DELEUZE, G.; GUATTARI, F. 28 de Novembro de 1974 - como criar para si um corpo sem órgãos (1980). In: . Mil Platôs: capitalismo e esquizofrenia. Tradução de Aurélio Guerra Neto et al. Rio de Janeiro: Editora 34, 2004. v. 3, p. 9-29.

FOUCAULT, M. A Hermenêutica do Sujeito (1981-1982). In Resumo dos Cursos do Collège de France (1970-1982). Tradução de Andréa Daher. Rio de Janeiro: J. Zahar, 1997. p.118-134.

. Subjetividade e verdade (1980-1981). In: Resumo dos Cursos do Collège de France (1970-1982). Tradução de Andréa Daher. Rio de Janeiro: J. Zahar, 1997. p. 107-115.

. A Escrita de Si (1983a). In: MOTTA, M. B. da (Org.). Ética, Sexualidade, Política: Michel Foucault. Tradução de Elisa Monteiro e Inês A. D. Barbosa. Rio de Janeiro: Forense Universitária, 2004. Coleção Ditos \& Escritos, v. V, p. 144-162.

. O Uso dos Prazeres e as Técnicas de Si (1983b). In: MOTTA, M. B. da (Org.). Ética, Sexualidade, Política: Michel Foucault. Tradução de Elisa Monteiro e Inês A. D. Barbosa. Rio de Janeiro: Forense Universitária, 2004. Coleção Ditos \& Escritos, v. V, p. 192-217.

. O Cuidado com a Verdade (1984a). In: MOTTA, M. B. da (Org.). Ética, Sexualidade, Politica: Michel Foucault. Tradução de Elisa Monteiro e Inês A. D. Barbosa. Rio de Janeiro: Forense Universitária, 2004. Coleção Ditos \& Escritos, v. V, p. 240-251.

. O Retorno da Moral (1984b). In: MOTTA, M. B. da (Org.). Ética, Sexualidade, Política: Michel Foucault. Tradução de Elisa Monteiro e Inês A. D. Barbosa. Rio de Janeiro: Forense Universitária, 2004. Coleção Ditos \& Escritos, v. V, p. 252-263.

. AÉtica do Cuidado de Si como Prática da Liberdade (1984c). In: MOTTA, M. B. da (Org.). Ética, Sexualidade, Politica: Michel Foucault. Tradução de Elisa Monteiro e Inês A. D. Barbosa. Rio de Janeiro: Forense Universitária, 2004. Coleção Ditos \& Escritos, v. V, p. 264-287.

GIL, J. Metamorfoses do corpo. Lisboa: Relógio D’Água, 1997.

HEMSY DE GAINZA, V. Conversas com Gerda Alexander: vida e pensamento da criadora da Eutonia. Tradução de Cíntia A. de Carvalho. São Paulo: Summus, 1997.

TEIXEIRA, L. Conscientização do movimento: uma prática corporal. São Paulo: Caioá, 1998. 